Canadian Journal of Higher Education Revue canadienne d'enseignement supérieur

Volume 45, No. 4, 2015, pages $261-282$

\title{
Special Consideration in Post-Secondary Institutions: Trends at a Canadian University
}

Joelle Zimmermann \& Stuart B. Kamenetsky

University of Toronto

Syb Pongracic

Ryerson University

\begin{abstract}
This study examined trends in the practice of granting special consideration for missed tests and late papers in colleges and universities. We analyzed a database of 4,183 special consideration requests at a large Canadian university between 1998 and 2008. Results show a growing rate of requests per enrolment between 2001 and 2007. Although university officials and faculty are concerned that request making is excessive, an in-depth investigation of request making by the number of requests per student, request rate by course difficulty, grade point average, and illness-related work absences in the general population fails to support suspicions of dishonest behaviour. Furthermore, demographic variables-aside from part-time versus full-time student status, and to a lesser degree socio-economic status-do not distinguish students who made frequent requests from those who made few. We discuss potential explanations for the increase in requests for special consideration.
\end{abstract}

\section{Résumé}

Cette étude examine les tendances quant à l'octroi de dérogations pour la reprise de tests manqués ou la remise tardive de travaux académiques dans les collèges et universités. Nous avons analysé une base de données compilées 
entre 1998 et 2008 contenant 4183 demandes de dérogation provenant d'une grande université canadienne. Les résultats montrent une augmentation du taux de demandes de dérogation par inscription entre 2001 et 2007. Bien que les autorités universitaires et les membres de facultés s'inquiètent que les demandes de dérogation soient excessives, une analyse poussée du nombre de requêtes par étudiant, du taux de requêtes en fonction du niveau de difficulté des cours, de la moyenne cumulative de l'étudiant, et des absences au travail liées aux conditions de santé dans la population générale ne soutient pas l'hypothèse d'un comportement malhonnête. Par ailleurs, mis à part l'opposition des statuts d'étudiants à temps partiel et à temps plein, ainsi que, dans une moindre mesure, le statut socio-économique, les variables démographiques ne permettent pas de distinguer les étudiants qui font de multiples requêtes de ceux qui en font moins. Nous discutons des potentialités expliquant l'augmentation des demandes de dérogations.

\section{Special Consideration Policies and Procedures}

Special consideration refers to the adaptation of a grading process because of circumstances beyond a student's control that negatively affect his or her academic performance. This practice is common in secondary and post-secondary institutions and is intended to maintain fairness in evaluation without creating an advantage to the affected student (Rodeiro, 2010). The criteria for granting special consideration vary by university but for the most part include either a documented medical condition or evidence of temporary disability or bereavement (de Lambert \& Williams, 2006). Other reasons may include accidentally missed tests, automobile accidents, religious observances, and participation in mandatory activities such as military service. One study conducted at an Australian university found that the majority of requests resulting in alternative scheduling of missed tests or examinations were due to illness or physical injury (Croucher, 1995). If granted, special consideration includes a variety of practices such as extending deadlines for papers, reducing penalties for late assignments, allowing students to write makeup tests or examinations at a later date, or adjusting grades (Rodeiro, 2010).

Students are typically required to provide evidence or documentation to verify the condition meriting special consideration (Croucher, 1995). If the condition is medical in nature, this often includes a doctor's note dated on the day of the missed test to be submitted along with the special consideration application. For example, at the University of Toronto (Mississauga), a major North American university, the special consideration process is as follows: On the day of a missed assessment, students must first declare their absence online and then submit the request for special consideration to the department concerned. Evidence that a physician was consulted within a day of the illness must also be provided, using a university medical form. The medical note must indicate that the student was unable to take the test on the examination date for medical reasons. Requests are handled by the department. If the department considers the case worthy of special consideration, a makeup test, if required, will take place within two weeks of the missed test (University of Toronto Mississauga, 2011).

Post-secondary institutions differ from secondary schools in their policies and procedures for requesting and granting special consideration. For instance, Rodeiro (2010) 
reported that in British secondary schools, the school submits special consideration requests to a national awarding body that is responsible for dealing with post-examination adjustment of grades. Thus, special consideration requests cannot be submitted directly by parents or students, and the school plays a primary role in the process. Canadian secondary schools do not deal with special consideration requests through an awarding body, however, and in this regard are more similar to post-secondary institutions. In post-secondary institutions, such as the one examined by Croucher (1995), where it is normally the student's responsibility to submit a request, policies and procedures tend to be less flexible and in most cases require official documentation such as a medical note.

The governing body in charge of reviewing and granting special consideration varies by university. Often, university-wide guidelines for special consideration requests have been developed to standardize this process in order to ensure fair treatment across academic departments and among students. In other cases, individual departments are entirely responsible for such decision making (Croucher, 1995). Exceptions are handled on an individual basis, and decision making may extend beyond departmental or institutional guidelines. For example, a student may informally ask a professor for another opportunity to take a missed test or permission to submit a late paper without penalty, perhaps to boost a borderline grade (de Lambert \& Williams, 2006). Differential implementation of rules by teaching staff for a diverse student body with varying circumstances and special needs emphasizes the lack of standardization in the process and the need for further research in the field. Thompson, Phillips, and De Lange (2006) proposed the following key decision-making principles to guide the granting of special consideration by post-secondary institutions: The burden of proof is on the applicant; an expert must provide proof of the student's disadvantage and the length of time that the disadvantage may affect the student's academic performance; the expert must be credible; and the final decision to grant special consideration must be reasonable.

\section{Trends in Special Consideration}

Administrators, policy makers, and academics are increasingly concerned about the perceived rise in requests for special consideration that cannot be explained by adjusting for larger student enrolments (Rodeiro, 2010). Croucher (1995) reported a sharp increase in the number of special consideration requests at Macquarie University in Sydney, Australia, between 1979 and 1993, greater than the rise in student enrolment. Rodeiro (2010) reported similar findings among British high school students between 2000 and 2009. Although a direct comparison of these two studies is difficult given the varying systems that govern secondary and post-secondary institutions, and different student demographic samples (including motivational and attitudinal factors among students), these studies still underscore a concerning trend in academia. Further, aside from these two known studies that have examined this trend empirically, the growing concern is often based on anecdotal evidence. Rodeiro (2010) suggests that the increase in requests may be due to three factors: students being more informed about the conditions under which they are eligible for special consideration; awarding bodies being more inclusive in meeting the needs of disadvantaged students; and students having ulterior (i.e., dishonest) motivations for requesting special consideration. 
University administrators respond to changes in special consideration trends by amending policy. In the mid-1990s, some Australian universities prohibited one-day absences that occurred on the day of a test from being given special consideration (Croucher, 1995). This policy was successful in decreasing anecdotal reports of special consideration requests that were difficult to verify. Similarly, some Canadian universities have tried to limit the number of requests a student can make per term or the number of requests that can be made for late submission of mid-term papers and assignments (McMaster University, 2008). Although such measures are intended to reduce disingenuous requests, they may also be unfair to students who have chronic health conditions or personal difficulties that warrant repeated requests for special consideration.

\section{Demographic Factors}

Various demographic factors may affect and/or predict students' request-making behaviour. Younger students (under 30) who are female, studying full-time, international, in a quantitative rather than qualitative field, and academically weaker are more likely to request special consideration (Croucher, 1995; Rodeiro, 2010). The correlation between the rate of requests per enrolment and certain demographic factors, such as gender, has been shown to be quite strong (Croucher, 1995). Female students tend to cite health issues as the reason for skipping class in university more frequently than male students (Gump, 2004), a fact that may explain the higher overall rate of request making among females. The request rate of students under 30 was found to be twice as high as that of students over 30 (Canada, House of Commons, Standing Committee on Health, 2012). This is contrary to the expectation that the oldest cohort of students (over 60) would have the greatest number of requests because of a higher prevalence of chronic medical problems. Motivations for request making may also differ by age and/or school year. For instance, students in higher years of university are more likely than first-year students and sophomores to provide more trivial reasons for skipping class, such as inclement weather (Gump, 2004). Socio-economic status may also affect request making. Several studies have highlighted the association between family income and participation in university education. One study found that youth with parental income below $\$ 25,000$ were less than half as likely to have a university education as their peers with a family income over $\$ 100,000$ (Drolet, 2005). Statistics Canada's Youth in Transition Survey reported that youth from high-income families have 50\% university participation rates, compared with only $31 \%$ for youth from low-income families (Finnie, Mueller, Sweetman, \& Usher, 2010). Thus, it is possible that students from lower socio-economic backgrounds face greater financial and personal challenges that may limit their ability to keep up with academic responsibilities, and consequently these students may rely on special consideration requests as a method of coping. When investigating request making by socio-economic status, however, it is important to consider that a smaller proportion of these students attend university to begin with.

\section{Concerns Regarding Special Consideration}

Much evidence exists to suggest that fraudulent behaviour at post-secondary institutions is on the rise, with some studies reporting as many as 50\% to $90 \%$ of students having engaged in academic misconduct (Aurich, 2012; Chapman, Davis, Toy, \& Wright, 2004; Graham, Monday, O’Brien, \& Steffen, 1994; Schmelkin, Gilbert, Spencer, Pincus, \& Silva, 
2008). One study found that only $48 \%$ of students consider acts such as feigning an illness or providing false excuses for missing an exam to be dishonest (Carpenter, Harding, Finelli, Montgomery, \& Passow, 2006). Interestingly, the profiles of students who engage in academic misconduct, including falsifying documents or feigning illness to gain academic advantage, match the demographics of a typical requester (younger, full-time status, low academic standards), as outlined in both Croucher's (1995) and Rodeiro's (2010) studies.

Increasingly competitive academic environments with stricter admission standards to coveted graduate and professional programs may be one explanation for the rise in academic misconduct. Indeed, increases in the incidence of plagiarism and substance abuse for the purpose of improving academic performance have been widely documented (Armitage, 2013; Aurich, 2012; Chapman et al., 2004; Graham et al., 1994; Schmelkin et al., 2008). Alternative anecdotal evidence suggests that the increase in request-making behaviour is due primarily to a greater number of illness-related absences. If the general population were getting sicker, a proportional increase in the number of requests due to illness would be justified. However, there is no evidence for such a trend (Statistics Canada, 2012). Of particular concern is the increase in student absences due to medical conditions that are difficult to diagnose, such as gastrointestinal illness and migraine headaches (Aronoff et al., 2007).

The aim of our study was to examine the pattern of special consideration requests over time and to determine whether relevant academic and demographic variables predict request-making behaviour. An investigation of this sort seems timely, as awarding bodies are becoming increasingly suspicious of the legitimacy of requests and this suspicion may lead institutions to create and enforce stricter university policies. On the other hand, draconian policies may be unfair to deserving students by denying them the right to be granted special consideration due to circumstances beyond their control. Enacting stricter policies must therefore be grounded in decisive empirical evidence documenting that the increase in special consideration requests beyond general enrolment increases is indeed due to a rise in the number of illegitimate requests.

\section{Method}

As the largest and the leading university in Canada, the University of Toronto is an ideal place to examine special consideration policies, procedures, and trends. We analyzed data on special consideration requests for missed tests and late submission of term work, as well as demographic and other administrative data, for students taking psychology courses between 1998 and 2008. Although this was a sample of convenience, it is likely representative of the undergraduate Faculty of Arts and Sciences student population at this university, since the majority of psychology students are majors who are required to complete an additional major in the humanities, the social sciences, or the life sciences. For obvious methodological reasons, this study was descriptive and correlational and faced common challenges associated with using academic records for research purposes, such as strict policies on the protection of personal information (University of Toronto, 2011). Requests that were denied (less than $0.01 \%$ of all requests) were removed from our database. Since guidelines for request making are explicitly stated on the university website (University of Toronto Mississauga, 2011), few students submit requests if they know they do not meet the submission requirements. Requests that are made without proper documentation are typically not granted. 
We investigated trends in request making, including the frequency of requests per student, the proportion of requests for missed term tests versus late submission of term work, and the reasons for request making. We also explored the associations between course difficulty, course year, student grade point average (GPA), and request making. We examined characteristics of students who requested special consideration, including the correlation between request making and age, gender, and socio-economic status. Accommodations for students with disabilities are handled through a separate process and thus were not included in this study.

\section{Participants}

We examined records of 2,105 students who made requests (1,586 females and 519 males). Requesters' ages ranged from 17 to $59(M=21.52, S D=3.83)$. Of these students, 1,091 attended full-time; the remaining 1,014 were part-time students. A number of students made multiple requests.

\section{Data Set}

Records for each individual request included student number, student age at request, gender, cumulative grade point average (CGPA), postal code, date of request, course code, and type of request (i.e., missed test or late submission). The reason cited for the request was recorded as either "medical" or "other." Requests with no provided reason were recorded as "unknown". Our analyses were based on the number of requests rather than the number of students making requests. Therefore, a student who made multiple requests had a greater impact on the results than a student who made only one request. However, a preliminary analysis based on the number of requesters (rather than requests) did not yield statistically significant differences. Requests that were incomplete because of missing data were excluded from the analyses. Requests may have been made either prior to the test, or up to one week after the test with a doctor's note from within a day of the missed test. However, these were not differentiated in our database.

\section{Data Transformation}

We converted request data to a by course data set, in which records were entered by course name and start session of the course (e.g., PSY100, Fall 2008). In this data set, course enrolment was standardized as full-year credit equivalents (FCEs), because twice as many requests would likely be made in a full-year course as in a half-year course. Information by course data included course session, start year, course average, enrolment, FCE enrolment (the number of students enrolled in courses when standardized by FCE), number of requests, and the percentage of requests per FCE enrolment.

\section{Results and Discussion}

\section{Overall Trends in Request Making}

Between 1998 and 2008, there were a total of 24,454 full-year course enrolments. Among these, results show, 4,183 requests were made in 498 individual courses. The request rate was thus approximately $17 \%$ of enrolment. With six evaluation measures on av- 
erage per full-credit course (as per course syllabi), the request rate was actually lower than $3 \%$. Ninety-two percent of all requests were due to missed term tests and $6 \%$ were for extensions of deadlines for term work. The remaining requests were due to a combination of both. Students are more likely to be sick for a short duration, resulting in missing a test, than for a long duration, which would justify an extension for submitting a term paper they had many weeks to prepare. Consequently, proving illness over a longer time period is more difficult. Moreover, because of the challenges associated with managing student assessment in large classes (Iipinge, n.d.), the majority of assessments at the University of Toronto are tests. Figure 1 depicts requests plotted alongside FCE enrolment. FCE enrolment decreased slightly between 1998 and 2001, followed by a steady increase from 2001 to 2005, and then a leveled off after 2005. The number of requests followed a similar pattern.

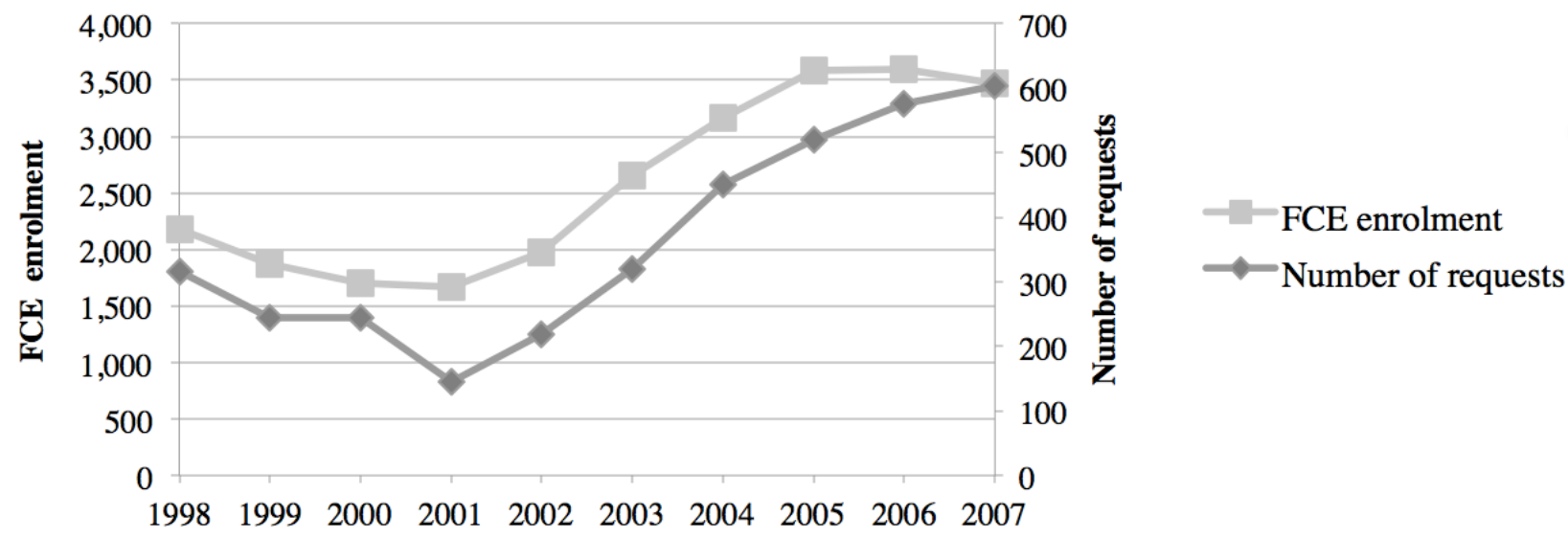

Figure 1. FCE enrolment and requests for special consideration.

The similar trends for requests and FCE enrolment depicted in Figure 1 initially suggest that the rate of request making did not outpace enrolment increases. To investigate whether it did, we calculated the number of requests per FCE enrolment for all courses for each academic year from 1998 to 2007. Results are displayed in Figure 2. A linear regression of the number of requests per FCE enrolment for individual courses in these years showed no significant increase from 1998 to 2007. However, Figure 2 indicates that requests per FCE enrolment began to rise only after 2001. Thus, two further analyses were conducted that separated requests made before and after 2001. As expected, linear regression analyses of requests per FCE enrolment for individual courses revealed no significant increase between 1998 and 2001, and a significant rise in requests per FCE enrolment between 2001 and $2007\left(F_{(1,345)}=7.24, p=.008\right)$ with a small $r$ value of 0.14 ; $\left(\beta=1.66 ; S E_{\beta}=0.62\right)$ was obtained.

The rate of requests per FCE enrolment remained relatively steady from 1998 to 2000, followed by a sharp drop in 2001. From 2001 onwards, requests per FCE enrolment grew steadily, rising above the requests per FCE enrolment in the years at the beginning of data collection (between 1998 and 2000). It should be noted that the drop from 2000 to 2001 coincided with the introduction of more competitive admission requirements to the psychology program. Possibly, the higher-achieving students who were admitted requested 
special consideration at a lower rate than their peers. However, no reported change in program admission standards was used to explain the request rate in the Croucher (1995) and Rodeiro (2010) studies. The association between request making and GPA will be reported later in this section.

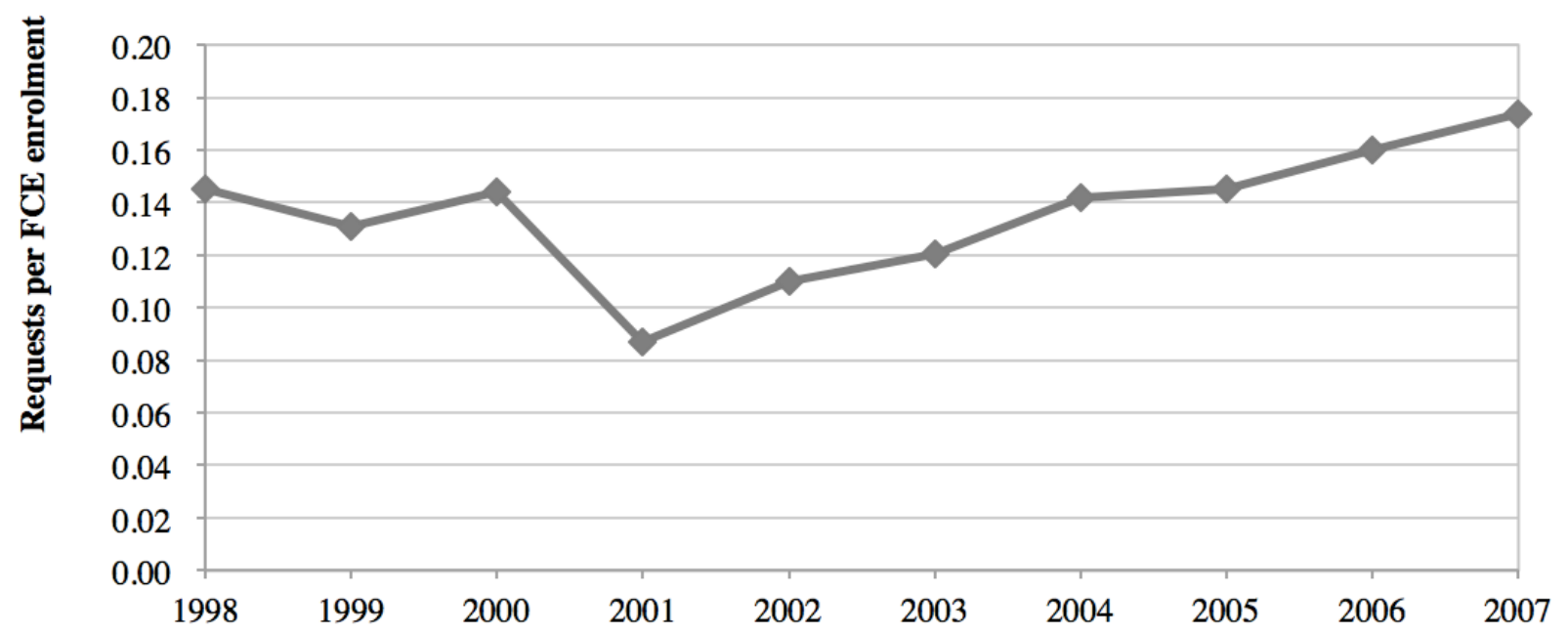

Figure 2. Rate of requests per FCE enrolment.

The increasing rate of requests per FCE enrolment from 2001 to 2007 is consistent with the recent trend found in the study of British secondary schools (Rodeiro, 2010) as well as with an earlier trend at an Australian university (Croucher, 1995). We found no parallels to the trends found in 1995 at Macquarie University in Sydney in the first few years of our data collection in the late 1990s. However, we found increases in request making at times in all three studies; these likely reflect ongoing changes in Western, English-speaking post-secondary institutions.

In order to determine how many requests individual students made, we created a frequency distribution of requests per student (see Table 1). The majority of students who made requests (60.9\%) made only one throughout their entire undergraduate education; 92.0\% of students made only four or fewer requests. The low frequency of multiple requests per student suggests that students were not making requests beyond legitimate need. During a student's four years at university, using an average of eight FCEs taken in psychology and six assessments per FCE, there are approximately 48 tests and papers that a student could potentially miss. Thus, a single missed assessment per student appears to be reasonable. As mentioned earlier, the majority of students did not make even one request during their entire university career and were not included in this database. Thus, multiple request makers (five or more requests) appeared to be a relatively small group, accounting for less than $8 \%$ of the request-making student population and a much smaller percentage of the entire student body. 
Table 1.

Frequency Distribution of Requests per Student

\begin{tabular}{lrcc}
\hline Number of requests & Frequency & Percent & Cumulative percent \\
\hline 1 & 1,282 & 60.9 & 60.9 \\
2 & 387 & 18.4 & 79.2 \\
3 & 171 & 8.1 & 87.4 \\
4 & 97 & 4.6 & 92.0 \\
5 & 57 & 2.7 & 94.7 \\
6 & 28 & 1.3 & 96.0 \\
7 & 33 & 1.6 & 97.6 \\
8 & 15 & 0.7 & 98.3 \\
9 & 13 & 0.6 & 98.9 \\
$10+$ & 22 & 0.7 & 100.0 \\
\hline
\end{tabular}

\section{Incomplete Data Transformation}

One challenge of this analysis was that the data set included incomplete records for students whose education began before 1998 and/or ended after 2008. To solve this problem we reanalyzed the data, including only students who had the potential of completing all course work leading to the completion of their degrees during the period of our data collection. Because the ratios of multiple to total requests in the original and adjusted data sets were not significantly different, we used the full data set for the remaining analyses.

\section{Rise in Medical Requests}

To investigate the possible reasons for the observed increase in requests per FCE enrolment since 2001, we separated requests into medical, other, and unknown reasons and examined the frequency of each type of request for each of the 10 years of the data set. Requests termed "medical" included illness and temporary disability; "other" requests included family members' medical conditions, court dates, social/personal reasons, accidents, catastrophic weather, deaths and funerals, course conflicts, religious observances, chronic disability, athletic competitions, and work-related reasons. The numbers of requests by year for medical, other, and unknown reasons are shown in Figure 3.

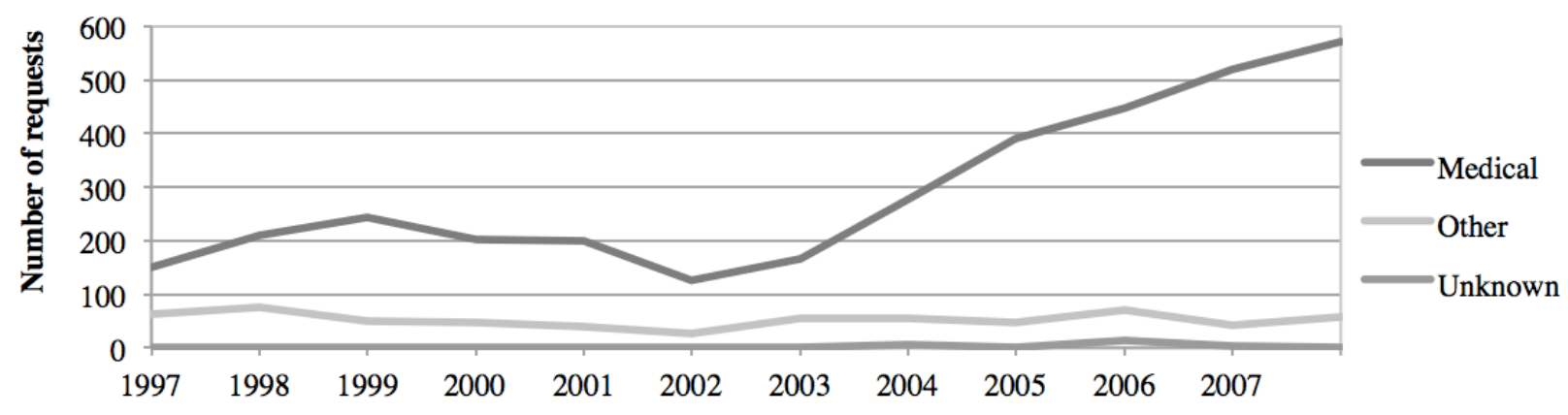

Figure 3. Frequency of medical and other requests. 
The number of requests based on medical reasons between 1998 and 2007 revealed a similar trend to that shown in Figures 1 and 2. Such requests remained relatively steady until 2001, followed by a drop in 2002 and a subsequent rise until the last year of data collection. Of interest is the relatively stable number of requests due to other or unknown reasons, compared with the rise in medical reasons since 2002/2003. Thus, it appears that the increase in enrolment correlated with an increase in requests for medical reasons only. A documented rise of illness rates in the general population would be expected to match the rise in medical requests among university students. The lack of increasing illness rates in general can explain why many faculty members suspect dishonest behaviour among request makers. Such behaviour has indeed been documented by previous research (Croucher, 1995; Rodeiro, 2010). To examine this empirically, our study compared the frequency with which students missed tests for medical reasons with the frequency of illness-related absences in the workplace. We examined the average number of missed workdays due to illness or disability for full-time employees in Canada (Statistics Canada, 2012, Table 7-2), selecting data for the cohort aged 20 to 24, the closest age category to that of the majority of university students. Work absences were available only for the years 2001 to 2007. We standardized data to a common unit of analysis-the actual number of days missed or requests made-divided by the number of opportunities to miss a workday or a test, respectively. For work absences, the average number of missed days at work per year was divided by the total number of working days in a year (235), taking into account vacation days and statutory holidays. For student request data, the total number of medical requests per year was divided by the total number of opportunities to request special consideration. The latter was the total FCE enrolment per year, multiplied by an average of six assessments per FCE.

Results indicate that the rate at which students requested special consideration was consistent with the rate of illness-related work absences. However, special consideration requests per enrolment increased between 2001 and 2007, while illness-related work absences remained relatively stable during these years, with a slight dip in 2004. In the last few years of data collection, special consideration request rates were similar to those of illness-related work absences. Perhaps during the more recent years of the study, students felt increasingly comfortable requesting special consideration for medical reasons. This may be a consequence of universities becoming less likely to refuse requests because of their increased awareness of students' rights (University of Toronto, 2012), translating into greater rates of request making. Also worth noting is that illness-related work absences may not be the best measure of illness rates in the general or student population. That is, similar motivations may cause employees to take a day off work and students to miss an assessment at school. The next analysis, of the association between request making and course difficulty, may reveal more on this subject.

\section{Course Difficulty and Request Making}

We investigated the association between request making and course averages to determine whether students made more requests in more challenging courses. If students were being dishonest, we might expect more requests to be made in difficult courses that typically have lower final course averages. A linear regression analysis showed that easier courses (i.e., with higher average grades) had significantly lower ratios of requests per 
FCE enrolment $\left(F_{(1,492)}=14.1, p<.001\right)$ with an $r$ value of $0.17 ;\left(\beta=-0.0065 ; S E_{\beta}=\right.$ o.0017). Although the association is weak, this finding suggests that at least some students may have been making requests to delay being tested on difficult course material. Alternatively, this request rate may have been related to higher rates of stress-related illness in more challenging courses.

\section{Request Making by Grade Point Average}

An association between CGPA and request-making behaviour can be explained in two different ways: A positive association would suggest that stronger students attempt to gain an unfair advantage by spreading out their tests to more manageable schedules. A negative association could suggest that while stronger students make requests based on need, academically weaker students who are not prepared to take tests as scheduled miss them in order to avoid failing grades. We found that the CGPAs of request makers were skewed toward the lower end of the spectrum. However, because university students' CGPAs are generally skewed in this way, we investigated how the CGPAs of request makers compare with those of the broader student population. Specifically, we examined the average annual request rate per student enrolled in the psychology program for each CGPA category. We obtained enrolment statistics by CGPA from 2013 (a sample of convenience, as we had access only to the latest CGPA distribution of the university population). We divided the total number of requests over the 10-year period by 10, and examined these as a proportion of 2013 enrolment figures. Figure 4 shows that the distribution of the rate of requests per student was skewed toward students with low CGPAs, suggesting that more students with lower CGPAs made requests $(W=0.76, p<.001)$. However, an analysis of multiple to total requests by CGPA revealed no significant differences across the GPA range. Thus, our results suggest that although students with low CGPAs may have been making more single requests (based on program enrolment statistics), multiple requests were not unusually common among students in the lower CGPA range.

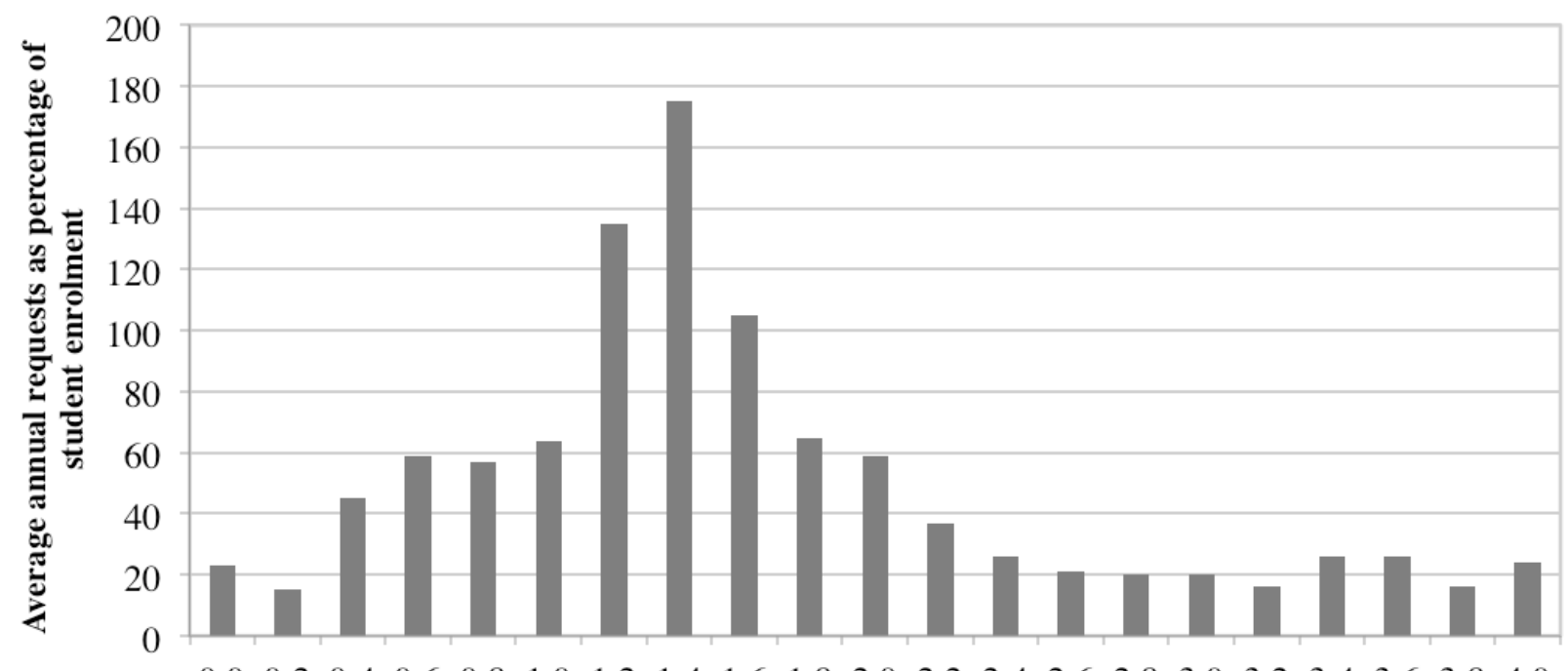

$\begin{array}{lllllllllllllllllllll}0.0 & 0.2 & 0.4 & 0.6 & 0.8 & 1.0 & 1.2 & 1.4 & 1.6 & 1.8 & 2.0 & 2.2 & 2.4 & 2.6 & 2.8 & 3.0 & 3.2 & 3.4 & 3.6 & 3.8 & 4.0\end{array}$

CGPA

Figure 4. Rate of requests by CGPA. 
Previous research has suggested that students with low academic standing have higher rates of academic misconduct, including feigning illness and falsification of documents to gain academic advantage (Marsden, Carroll, \& Neill, 2005). Croucher (1995) also found that students who submit special consideration requests typically have low GPAs. However, our study suggests that academically weaker students do not make a disproportionate number of multiple requests during their time at university. Moreover, caution must be applied when interpreting the finding that the rate of requests per student is skewed toward the low CGPA range, because the baseline CGPA data that were available to us were from 2013 and outside of the years of data collection for this study. While it is possible that the CGPA of the university population may have shifted over time, it is very unlikely that this shift was significant over the span of a few years. Interestingly, Rodeiro (2010) found that higher-achieving students made a greater number of requests than lower-achieving students. Thus, the association between student performance in school and request making appears to be inconsistent across the literature and may depend on a variety of factors.

\section{Demographics: Age, Year, Gender, Part-Time vs. Full-Time Status, and Socio-economic Status}

To examine the impact of student demographics on request making, we compared the demographic variables of students who had either many or few requests. To investigate the association between age and request making, we divided requests on the basis of age at time of request. The age of request makers was skewed toward the lower end of the adult age spectrum, consistent with the age distribution of the student population. To determine whether there is in fact an association between age and request making, we calculated the number of student requesters by age as a proportion of the number of students enrolled in an undergraduate psychology program in 2013 by age category (see Figure 5). As in the CGPA analysis, we divided the total number of requests over the 10-year period in each age group by 10 to obtain an average request rate per year. We examined these as a proportion of the 2013 enrolment. While using a 2013 sample was not ideal (see previous section), the age distribution of university students has not actually changed much from the early 1990 s to the late 2000 (Dale, 2013).

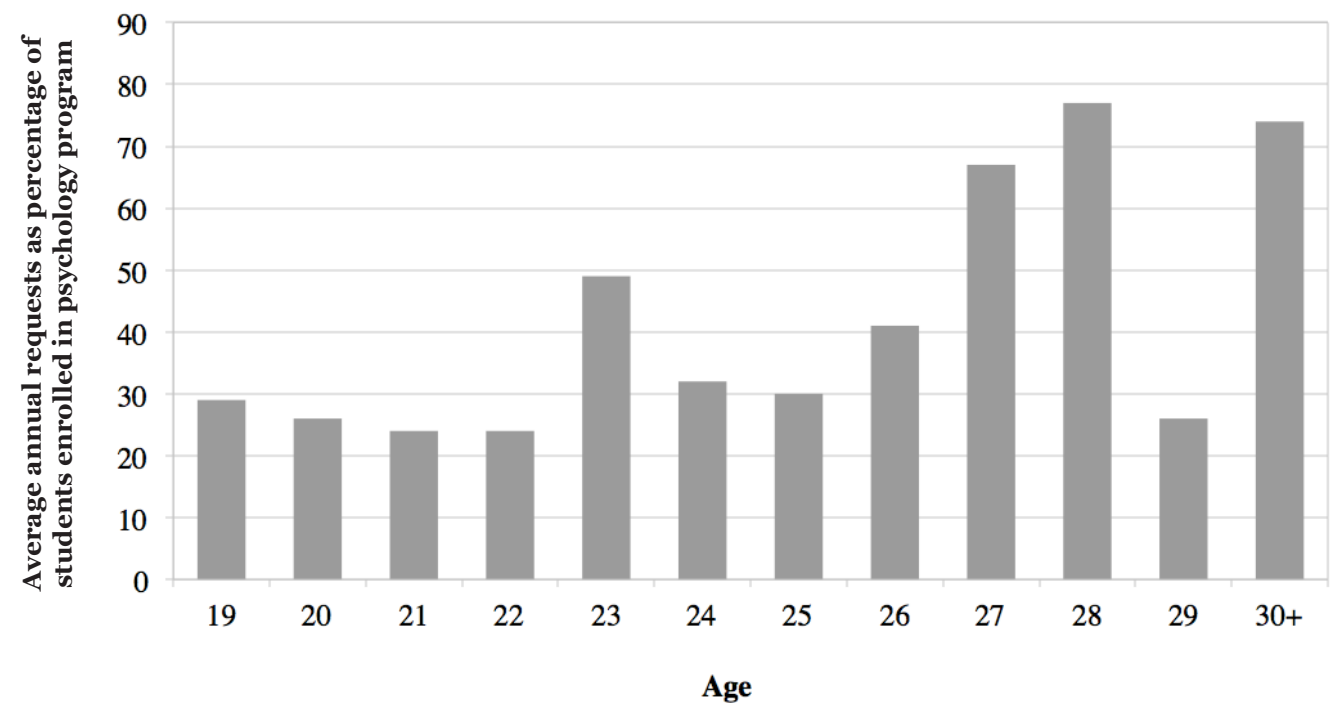

Figure 5. Rate of requests by age. 
Results suggest that older students appear more likely to make requests than their younger counterparts. However, a comparison of the ratio of multiple to total requests by age group revealed no significant difference. These results contradict both Croucher's (1995) finding that younger students have a higher request rate and the work of Rodeiro (2010), who found that 16-year-olds make more requests than 14-year-olds. The latter finding may be explained by more competitive motivations among 16-year-olds, who may be preparing for university applications. Moreover, high school students are primarily adolescents who experience more rapid developmental changes compared with university students, who are for the most part adults.

Another possible explanation for the inconsistency between the results of these studies and our study is that Croucher (1995) and Rodeiro (2010) calculated the rate of requests per number of students in each age group, while our primary measure was the ratio of multiple to single requests. Moreover, differences in academic attitudes may be related to the inverse association between age and request making in the studies. For example, differences in academic motivations and attitudes have been found between first- and fourth-year university students, with the latter group demonstrating greater dedication to their academic responsibilities (Barlow \& Fleischer, 2011; Taylor \& House, 2010). Indeed, academic attitudes have been linked to behaviours such as class attendance (Gump, 2006). If avoiding academic responsibilities is indeed a sign of immaturity, then we would expect more-advanced students to make fewer special consideration requests. We therefore examined the ratios of requests per FCE enrolment for students in different years.

We excluded fourth-year request data because both enrolments and requests were low, and because fourth-level psychology courses at the University of Toronto are reserved primarily for high-achieving students who meet strict course admission standards. Results showed similar overall trends across first-, second-, and third-year courses resembling that of the sample as a whole. That is, requests per FCE enrolment bottomed in 2001, then began to increase. Interestingly, the ratio of requests per FCE enrolment appeared lowest in first-year courses $(M=0.11, S D=0.13)$, followed by second-year courses $(M=0.16, S D=0.15)$, and appeared highest in third-year courses $(M=0.19, S D=0.19)$. However, a one-way ANOVA of requests per FCE enrolment in first-, second-, and thirdyear courses revealed that the apparent trend in ratio per FCE enrolment by year was not significant. This finding contradicts the notion that request making would decline as students gain greater maturity and dedication as they progress through their programs. The similar trends in requests per FCE enrolment across first-, second-, and third-year courses and the lack of association between age and request making suggest that if indeed students do mature during the course of their university education, this has little effect on their request-making behaviour.

An analysis of request making by gender revealed that, compared with male students, female students made the majority of total requests, as well as a greater number of multiple requests. Taking into account the uneven gender distribution (58\% females, $42 \%$ males) of undergraduate Arts and Sciences students at the university (University of Toronto, 2006), we calculated that requests by female students were three times more frequent than those made by males ( $78 \%$ and $22 \%$ respectively). A one-way goodness of fit chi-square test confirmed that this gender difference is significant $\left(\chi_{2}(1)=100.06, p<\right.$ .005). Greater request making by female students was also found in Croucher's (1995) 
study, though requests were not divided into medical and nonmedical justifications. The Gump (2004) study showed that women are more likely to cite health as the reason for skipping class compared with men, suggesting that women may request special consideration for medical reasons to a greater extent than men. However, despite female students' higher request rate as a group, an investigation of the ratio of multiple to total requests showed that female students did not make a disproportionate number of high-frequency requests compared with males. Together, these findings suggest that while female students may legitimately require at least a single sick day for health-related reasons, they do not make an excessive number of requests. In fact, past research shows that women engage in academic misconduct slightly less often than men (Athanasou \& Olasehinde, 2002).

We also examined the frequency of requests by part-time and full-time status. We found that part-time students were more likely to make requests (52\%) compared with their full-time counterparts (48\%). Taking into account the greater proportion of fulltime compared with part-time students (90\% and 10\%, respectively) in undergraduate Arts and Sciences programs at the university (University of Toronto, 2006), we found the number of requests made by part-time students was actually 10 times higher than the number of requests made by full-time students. A one-way goodness of fit chi-square test confirmed that part-time students indeed made a significantly disproportionately higher number of requests compared with full-time students $\left(\chi^{2}(1)=1263.79, p<.005\right)$.

Although single requests were more common among full-time students, reflecting the distribution of the student population, part-time students made up the majority of highfrequency requesters. It may be the case that part-time students are more likely to have chronic medical conditions and thus can commit only to part-time studies (Online Colleges, n.d.). Part-time students may also be overwhelmed with nonacademic responsibilities, resulting in higher levels of stress (Robotham, 2012) and consequently stress-related illnesses. The association between stress and physical illness has been well documented, with increasing rates of stress-related illnesses being reported in the general population (Wright, 2014). The tendency for part-time students to make more multiple as opposed to single requests is inconsistent with the work of Croucher (1995), who found the rate of requests per enrolment to be higher among students studying full-time. This discrepancy may be due to the different measures of request making used in our study and Croucher's (1995) study. Moreover, the profile of a typical part-time student has changed since Croucher's (1995) study was conducted. A growth in the proportion of younger part-time students (Association of Universities and Colleges of Canada, 2011) is changing the perception of the part-time student as an older working parent. Young students may switch to part-time status in order to keep up with obligations such as work or family, or to reduce their course load in an effort to do better academically in a highly competitive environment. These young and overwhelmed part-time students may be making the requests in our study, but in Croucher's (1995) study, the part-time students were older and more mature, and it was the younger, full-time students who were making requests. Moreover, cultural or societal factors (Robotham, 2012) may also explain the different findings of these studies. For example, tuition rates and educational funding affect post-secondary students' need to find employment while being enrolled in school (Robotham, 2012). Working a few hours per week may not have much effect on academic performance compared with the negative consequences of working the longer hours necessary to support 
nonsubsidized education (Kulm \& Cramer, 2006). Students paying for tuition may switch to part-time study and work longer hours to afford their university education, which may have implications for request-making frequency.

We examined socio-economic level in relation to request frequency to determine whether it affects students' ability to meet academic requirements, as determined by their ability to write tests and submit papers as scheduled. As we did not have direct access to students' parental income, we used family median income as obtained from students' permanent address postal codes (Statistics Canada Census, 2006) as an estimate of socioeconomic status. Foreign and incomplete addresses were excluded from the analysis. We divided incomes into five income groups as reported by Drolet (2005) and determined the total number of requests by income range. Previous studies have shown that youth from low-income families are less likely to participate in university education than their peers. We therefore compared the socio-economic status of request makers with that of university students as a whole rather than with that of the general population (Drolet, 2005; Finnie et al., 2010). A one-way goodness of fit chi-square test confirmed that request makers had lower parental incomes compared with the general university population ( $\chi^{2}$ $(4)=235.92, p<.001)$. It is important to note, however, that the Statistics Canada report included university participation rates by family income based on students' actual parental income (Drolet, 2005). For example, 11\% of students in university have a parental income of below $\$ 25,000$ (Drolet, 2005). However, the parental incomes of the request makers that we studied were all higher than $\$ 25,000$. Thus, although there may be students in our sample whose actual parental incomes fell below $\$ 25,000$, these were not captured because of the sampling method that we used.

We also examined the ratio of multiple to total requests to investigate whether students from lower-income families were more likely to make a disproportionately larger number of requests (i.e., more multiple requests). As shown in Table 2, the ratio of multiple to total requests remained stable across income ranges. The exceptions were the lowest income bracket (below \$25,00o), where no requests were made by students in this group, a result presumably attributable to the different measures of parental income used in our study and by Drolet (2005); and the $\$ 25,000$ to $\$ 50,000$ income bracket, where the majority of multiple requests ( 11 requests) were made by one student. We conclude that although the socio-economic status of request makers differs from the distribution of socio-economic status in the general university population, students from lower-income groups are not making frequent (multiple) requests any more than would be expected.

\section{General Discussion}

The goal of our study was to examine patterns in request making among university undergraduate students over a 10-year period as well as to profile the types of students who most commonly make requests for special consideration. A preliminary investigation revealed that there was an increase in request making that was slightly higher than the rise in enrolment and that the rate of requests steadily increased from 2001 until 2007 following the implementation of new program admission requirements. This rise in requests paralleled the increase in medical requests during the same period. There were more medical requests than nonmedical ones; the pattern of requests made for nonmedical reasons was more stable. The overall rise in requests since 2001 was consistent for 
Table 2.

Frequency Distribution of Requests by Family Median Income

\begin{tabular}{lcccccc}
\hline Income range & $\begin{array}{c}\text { Proportion } \\
\text { of students } \\
\text { in university } \\
\text { with given } \\
\text { parental } \\
\text { incomes }\end{array}$ & $\begin{array}{c}\text { Number of } \\
\text { requesters }\end{array}$ & $\begin{array}{c}\text { Total } \\
\text { number of } \\
\text { requests }\end{array}$ & $\begin{array}{c}\text { Number } \\
\text { of single } \\
\text { requests }\end{array}$ & $\begin{array}{c}\text { Number of } \\
\text { multiple } \\
\text { requests }\end{array}$ & $\begin{array}{c}\text { Ratio of } \\
\text { multiple } \\
\text { to total } \\
\text { requests }\end{array}$ \\
\hline $\begin{array}{l}\text { Under } \$ 25,000 \\
\text { 0.106 }\end{array}$ & 0 & & & & \\
$\begin{array}{l}\text { \$25,000- } \\
\$ 50,000\end{array}$ & 0.220 & 25 & 64 & 10 & 15 & 1.5 \\
$\begin{array}{l}\$ 0,001- \\
\$ 75,000\end{array}$ & 0.244 & 488 & 944 & 294 & 194 & 0.66 \\
$\begin{array}{l}\$ 75,001- \\
\$ 100,000\end{array}$ & 0.218 & 1,274 & 2,481 & 790 & 484 & 0.61 \\
$\$ 100,000+$ & 0.212 & 133 & 291 & 82 & 51 & 0.62 \\
\hline
\end{tabular}

Note. Statistics of students attending university (column 2) are based on proportion of Canadian students by parental income in 2001. University participation data are based on statistics from Drolet (2005).

first-, second-, and third-year students. Moreover, while the frequency of missed tests and the frequency of illness-related work absences per opportunity were within the same range, illness-related work absences remained stable while request rates increased. The rate of request making in more challenging courses only slightly exceeded that in less challenging courses. While the rate of requests per student was slightly higher for students with low CGPAs, such students did not make a disproportionate number of multiple requests. An analysis of demographic trends revealed that part-time students request special consideration more frequently than their full-time peers. Although students from low socio-economic backgrounds may be more likely to make requests, multiple requests are equally common among all socio-economic groups, with the exception of the lowest group, where the sample size was too small to draw conclusions and a high number of multiple requests were made by a single student. We found other demographic factors including year of study, age, and gender to be unrelated to request-making frequency.

The overall rise in request rates was consistent with faculty concerns about this cohort of students. The increase in requests per enrolment, and in particular the disproportionate rise in medical as opposed to nonmedical requests, appear consistent with evidence of a recent increase in cheating behaviour (Christensen Hughes \& McCabe, 2006). Because universities tend not to disclose statistics relating to academic misconduct, this may actually be a greater problem than what is currently reported in the literature. The anecdotally reported increase in medical notes for conditions that are difficult to diagnose, such as gastrointestinal illnesses or migraines, is also consistent with this explanation. Future research should investigate how trends in request making for such conditions compare with trends of other, more easily determined medical conditions in order to understand the potential reasons behind rising rates of request making. 
Although the increasing request rates found in our study suggest a rise in cheating behaviour among the current cohort of students, our investigation of various factors does not support concerns expressed in earlier research that request-making behaviour is excessive or problematic (Croucher, 1995; Rodeiro, 2010). Most students enrolled did not miss a single test throughout their entire university education, and the vast majority of those who made requests made only one request during their four or more years in university. Moreover, the comparison of request making with illness-related work absences suggests that the rates of missed tests and missed days at work per opportunity were within the same range. In addition, the finding that the ratio of multiple to single requests was equal across the GPA range does not support suspicions that academically weaker students are making a disproportionate number of requests to gain an academic advantage.

The question remains why students are increasingly making medically related special consideration requests, while illness-related absences in the workplace have remained relatively stable. Possible explanations include greater leniency on the part of the administration, a greater focus on students' rights, and/or greater self-advocacy on the part of students. Although many workplaces have unions that have long negotiated benefits such as sick leave, university students are still not in a position to negotiate their rights as effectively. More lenient policies along with student advocacy may have led to an observed increase in appropriate requests that previously would not have been made; but they may also have made it possible for universities to accept more requests based on difficult-todiagnose medical conditions.

It is important to view the trends in our study as part of the larger social environment in which they occur. For example, employers and university administrators rely on doctors as credible decision makers who can reliably verify students' or employees' ability to fulfill academic or work duties. However, some physicians feel that they lack the knowledge and formal training to administer sick notes (Löfgren, 2010). Moreover, the high utilization of walk- in clinics by students combined with high patient demands may influence a doctor's decision to provide sickness certification (Campbell \& Ogden, 2006). Doctors may administer sick notes in the interest of efficiency and in the absence of a long-term relationship based on mutual trust (Marks, 1999).

\section{Demographic Trends}

Our analyses by age and year of study failed to find trends supporting previous findings of age-related or maturational changes in responsibility or attitude (e.g., Taylor \& House, 2010). Analysis by CGPA suggests that throughout their undergraduate education, students with lower CGPAs more commonly make requests than those with higher CGPAs. These students, however, are not high-frequency requesters, contrary to previous findings by Croucher (1995), and our results do not support current concerns by faculty that academically weaker students make excessive requests to gain inappropriate advantage. Moreover, although we did not find socio-economic status to be related to multiple request making, students from lower socio-economic backgrounds may be more likely to make a single request.

The only demographic variable that was significantly related to excessive request making was part-time versus full-time status. The majority of high-frequency requesters were part-time students, despite the greater rate of single requests among full-time students. 
Part-time status and low socio-economic status may be related to each other. For example, it may be the case that students from low-income families receive less financial support from their parents and are less able to study full-time because of financial burdens (Kapsalis, 2006). Thus, part-time students may request special consideration as a means of balancing school and work, or may become sick more often as a result of the cumulative effects of academic, personal, and financial pressures.

The differences between the demographic trends found in past research and in our study emphasize the variability in request-making behaviour across time and institutions, perhaps because of both student-related factors and different institutional practices. The trends reported here provide no evidence of dishonest request making, despite the rise in the request rate over time. These results, if replicated across various post-secondary institutions and academic disciplines, would suggest that Canadian universities are dealing with special consideration needs in an effective manner. In order to study academic misconduct, it seems necessary to focus first on the students who have been caught and investigate what characteristics, if any, distinguish these students from the broader student population.

\section{Limitations}

The data used in this study are archival data from one institution over a 10-year period. Thus, generalizations of our findings to other post-secondary institutions may be of limited value. Moreover, trends have been shown to vary across different disciplines (Croucher, 1995). Rates of request making in disciplines with more quantitative-based courses, for example, may be much higher than those reported in psychology courses (Croucher, 1995). Most important perhaps is the inherent challenge in distinguishing between students who make requests based on genuine need, and those who are motivated by dishonest reasons. The majority of our analyses were based on the measure of multiple to total requests, assessing those groups of students who make a disproportionate number of multiple requests, which may be interpreted as excessive request making. Undoubtedly, however, at least some of these students were experiencing legitimate circumstances beyond their control that resulted in repeated requests.

\section{Conclusions}

Although we found an increasing rate of requests, corroborating Croucher's (1995) and Rodeiro's (2010) findings, we did not find evidence to support suspicions of dishonest request-making behaviour. The limited literature surrounding special consideration and the inconsistencies between our study and these two earlier ones suggest that this practice merits far more empirical investigation and sharing of knowledge between postsecondary institutions. Although university regulations are grounded in legal obligations, policies, and procedures, best practices must be guided by empirical research in order to ensure that those in need are accommodated while those who have no genuine need are unlikely to gain an unfair advantage.

\section{Acknowledgements}

The authors wish to thank Jodie Stewart for maintaining the data set used for this study, Emmanuel Nikiema for the French translation of the abstract, and Christina Dimakos for editorial comments. 


\section{References}

Armitage, C. (2013, March 12). Students abusing drugs to improve performance. The Sydney Morning Herald. Retrieved from http://www.smh.com.au/national/health/ students-abusing-drugs-to-improve-performance-20130309-2fsdy.html

Aronoff, G. M., Mandel, S., Genovese, E., Maitz, E. A., Dorto, A. J., Klimek, E. H., \& Staats, T. E. (2007). Evaluating malingering in contested injury or illness. Pain Practice, 7, 178-204. doi:10.1111/j.1533-2500.2007.00126.x

Association of Universities and Colleges of Canada. (2011). Trends in higher education: Volume 1, enrolment. Ottawa, ON: AUCC.

Athanasou, J. A., \& Olasehinde, O. (2002). Male and female differences in self-report cheating. Practical Assessment, Research \& Evaluation, 8(5). Retrieved from http:// PAREonline.net/getvn.asp? $\mathrm{v}=8 \& \mathrm{n}=5$

Aurich, D. M. (2012). Academic integrity, academic sabotage, and moral disengagement in higher education (Doctoral dissertation). Retrieved from ProQuest Dissertations \& Theses database. (UMI No. 3539956)

Barlow, J., \& Fleischer, S. (2011). Student absenteeism: Whose responsibility? Innovations in Education and Teaching International, 48(3), 227-237. doi:10.1080/14 703297.2011.593700

Campbell, A., \& Ogden, J. (2006). Why do doctors issue sick notes? An experimental questionnaire study in primary care. Family Practice, 23(1), 125-130. doi:10.1093/ fampra/cmiog9

Canada, House of Commons, Standing Committee on Health. (2012). Chronic diseases related to aging and health promotion and disease prevention. Retrieved from http:// www.parl.gc.ca/content/hoc/Committee/411/HESA/Reports/RP5600467/hesarpo8/ hesarpo8-e.pdf

Carpenter, D. D., Harding, T. S., Finelli, C. J., Montgomery, S. M., \& Passow, H. J. (2006). Engineering students' perceptions of and attitudes towards cheating. Journal of Engineering Education, 95, 181-194. doi:10.1002/j.2168-9830.2006.tboo891.x

Chapman, K. J., Davis, R., Toy, D., \& Wright, L. (2004). Academic integrity in the business school environment: I'll get by with a little help from my friends. Journal of Marketing Education, 26(3), 236-249. doi:10.1177/0273475304268779

Christensen Hughes, J. M., \& McCabe, D. L. (2006). Academic misconduct within higher education in Canada. Canadian Journal of Higher Education, 36, 1-21. Retrieved from http://ojs.library.ubc.ca/index.php/cjhe/article/view/183537

Croucher, J. (1995). Increasing incidence of special consideration cases at university. HigherEducationResearch\&Development,14(1),13-20.doi:10.1080/0729436950140102

Dale, M. (2013). Trends in the age composition of college and university students and graduates. Education Matters: Insights on Education, Learning and Training in Canada, 7(5). Statistics Canada. Retrieved from http://www.statcan.gc.ca/pub/81004-x/2010005/article/11386-eng.htm\#a 
de Lambert, K., \& Williams, T. (2006). In sickness and in need: The how and why of special consideration for students. Assessment \& Evaluation in Higher Education, 31, 55-69. doi:10.1080/02602930500350182

Drolet, M. (2005). Participation in post-secondary education in Canada: Has the role of parental income and education changed over the 1990s? Ottawa, ON: Statistics Canada. Retrieved from http://publications.gc.ca/Collection/Statcan/11Foo19MIE/11Fo 019MIE2005243.pdf

Finnie, R., Mueller, R. E., Sweetman, A., \& Usher, A. (2010). New perspectives on access to postsecondary education. Education Matters: Insights on Education, Learning and Training in Canada, 7(1). Statistics Canada. Retrieved from http://www.statcan. gc.ca/pub/81-004-x/2010001/article/11152-eng.htm

Graham, M., Monday, J., O'Brien, K., \& Steffen, S. (1994). Cheating at small colleges: An examination of student and faculty attitudes and behaviors. Journal of College Student Development, 35, 255-26o. Retrieved from http://muse.jhu.edu/journals/journal_of_ college_student_development/

Gump, S. E. (2004). The truth behind truancy: Student rationales for cutting class. Educational Research Quarterly, 28(2), 48-57. Retrieved from http://files.eric.ed.gov/ fulltext/EJ718128.pdf

Gump, S. E. (2006). Guess who's (not) coming to class: Student attitudes as indicators of attendance. Educational Studies, 32(1), 39-46. doi:10.1080/03055690500415936

Iipinge, S. (n.d.). Challenges of large class teaching at the university: Implications for continuous staff development activities. Retrieved from http://people.math.sfu. ca/ vjungic/Lipinge.pdf

Kapsalis, C. (2006). Who gets student loans? Perspectives on Labour and Income, 18(2), 12-18. Retrieved from http://mpra.ub.uni-muenchen.de/25698/

Kulm, T. L., \& Cramer, S. (2006). The relationship of student employment to student role, family relationships, social interactions and persistence. College Student Journal, 4O, 927-938. Retrieved from https://www.questia.com/library/p1917/college-student-journal

Löfgren, A. (2010). Physicians sickness certification practices: Frequency, problems, and learning (Doctoral dissertation). Retrieved from http://publications.ki.se/xmlui/ handle/10616/38322

Marks, D. (1999). Disability: Controversial debates and psychosocial perspectives. New York, NY: Routledge.

Marsden, H., Carroll, M., \& Neill, J. T. (2005). Who cheats at university? A self-report study of dishonest academic behaviours in a sample of Australian university students. Australian Journal of Psychology, 57(1), 1-10. doi:10.1080/00049530412331283426

McMaster University. (2008). General academic requirements: Requests for relief for missed academic term work. Retrieved on April 10, 2014 from http://registrar. mcmaster.ca/calendar/2012-13/pg2246.html

Online Colleges. (n.d). College students living with a chronic condition. Retrieved from http://www.onlinecolleges.net/for-students/chronic-health-issues/ 
Robotham, D. (2012). Student part-time employment: Characteristics and consequences. Education + Training, 54(1), 65-75. doi:10.1108/00400911211198904

Rodeiro, C. L. V. (2010). Special consideration: A statistical investigation on the number of requests and the impact of the enhancement. Retrieved from

http://www.cambridgeassessment.org.uk/Images/109793-special-considerationa-statistical-investigation-on-the-number-of-requests-and-the-impact-of-theenhancements.pdf

Schmelkin, L. P., Gilbert, K., Spencer, K. J., Pincus, H. S., \& Silva, R.(2008). A multidimensional scaling of college students' perceptions of academic dishonesty. The Journal of Higher Education, 79, 587-607. Ohio State University Press. Retrieved from http://www.jstor.org/stable/25144694

Statistics Canada. (2006). 2006 census of population. Retrieved from https://www12. statcan.gc.ca/census-recensement/2006/index-eng.cfm

Statistics Canada. (2012). Work Absence Rates, 2011. Retrieved from http://www. statcan.gc.ca/pub/71-211-x/71-211-x2012000-eng.htm

Taylor, J., \& House, B. (2010). An exploration of identity, motivations and concerns of non-traditional students at different stages of higher education. Psychology Teaching Review, 16(1), 46-57.

Thompson, P., Phillips, J., \& De Lange, P. (2006). The assessment of applications for special consideration: A conceptual framework. Accounting Education, 15, 235-238. doi:10.1080/06939280600609276

University of Toronto. (2006). Facts and figures. Retrieved from http://www. utoronto.ca/sites/default/files/about/Facts_Figures_2006/Facts_Figures_20061283. pdf $\#$ page $=33$

University of Toronto. (2012). Rights and responsibilities. Retrieved from http://life. utoronto.ca/get-help/rights-responsibilities/

University of Toronto Mississauga. (2011). Missed tests/extensions. Retrieved from http://www.utm.utoronto.ca/iccit/about-us/policies/missed-testsextensions

University of Toronto. (2011). Access and Privacy Practices: General and Administrative. Retrievedfrom:http://www.provost.utoronto.ca/Assets/Provost+Digital +Assets/Provost/Provost+Digital+Assets/Provost/fippa.pdf

Wright, J. (2014, Aug. 18). Stress-related sick days rise by $70 \%$ in East of England public sector. BBC News. Retrieved from http://www.bbc.com/news/uk-englandsuffolk-28742359

\section{Contact Information}

Stuart B. Kamenetsky

Department of Psychology

University of Toronto Mississauga

stuart.kamenetsky@utoronto.ca 
Joelle Zimmermann is a psychology $\mathrm{PhD}$ student at the University of Toronto, where she also received her honours BSc and MA. Her research focus is in computational neuroscience, where she investigates neural networks using the Virtual Brain simulator of brain dynamics. Her interest lies in understanding the structural and functional correlates of cognitive decline in aging.

Dr. Stuart Kamenetsky serves as associate chair and director of the psychology undergraduate program at the University of Toronto Mississauga. He teaches courses on disability, cross- cultural psychology, and child development. He also conducts research on perceptions of disability images, building social capital in the disability community, and student accommodation in post-secondary education.

Syb Pongracic is completing her PhD in clinical psychology at Ryerson University in Toronto. Her current research focuses on decision making in clinical disorders such as obsessive-compulsive disorder (OCD) and gambling. She obtained her honours BSc at the University of Toronto Mississauga. Her master's thesis examined the neuropsychology of OCD in young adults. 